University of Massachusetts Amherst

From the SelectedWorks of Bethany Bradley

2012

Predicting how adaptation to climate change could affect ecological conservation: secondary impacts of shifting agricultural suitability

Bethany A Bradley 


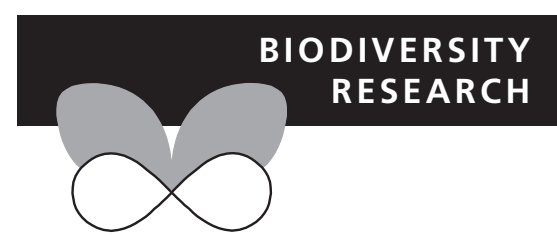

\section{Predicting how adaptation to climate change could affect ecological conservation: secondary impacts of shifting agricultural suitability}

Bethany A. Bradley ${ }^{1 \star}$, Lyndon D. Estes ${ }^{2}$, David G. Hole ${ }^{3}$, Stephen Holness ${ }^{4,5}$, Michael Oppenheimer ${ }^{2,6}$, Will R. Turner ${ }^{3}$, Hein Beukes ${ }^{7}$, Roland E. Schulze ${ }^{8}$, Mark A. Tadross ${ }^{9}$ and David S. Wilcove ${ }^{2,10}$

${ }^{1}$ Department of Environmental Conservation, University of Massachusetts, Amherst, MA 01003, USA, ${ }^{2}$ Program in Science, Technology, and Environmental Policy, Woodrow Wilson School, Princeton University, Princeton, NJ 08544, USA, ${ }^{3}$ Science and Knowledge Division, Conservation International, Arlington, VA 22202, USA, ${ }^{4}$ Park Planning and Development Conservation Services, South African National Parks, Humewood 6013, South Africa, ${ }^{5}$ Center for African Conservation Ecology, Department of Zoology, Nelson Mandela Metropolitan University, Port Elizabeth 6013, South Africa,

${ }^{6}$ Department of Geosciences, Princeton University, Princeton, NJ 08544, USA, ${ }^{7}$ Institute for Soil, Climate, and Water, Agricultural Research Council, Stellenbosch 2599, South Africa, ${ }^{8}$ School of Bioresources Engineering and Environmental Hydrology, University of KwaZulu-Natal, Pietermaritzburg 3209, South Africa, ${ }^{9}$ Climate Systems Analysis Group, University of Cape Town, Rondebosch 7701, South Africa, ${ }^{10}$ Department of Ecology and Evolutionary Biology, Princeton University, Princeton, NJ 08544, USA

${ }^{*}$ Correspondence: Bethany A. Bradley, Department of Environmental Conservation, University of Massachusetts, Amherst, MA 01003, USA.

E-mail: bbradley@eco.umass.edu

\section{ABSTRACT}

Aim: Ecosystems face numerous well-documented threats from climate change. The well-being of people also is threatened by climate change, most prominently by reduced food security. Human adaptation to food scarcity, including shifting agricultural zones, will create new threats for natural ecosystems. We investigated how shifts in crop suitability because of climate change may overlap currently protected areas (PAs) and priority sites for PA expansion in South Africa. Predicting the locations of suitable climate conditions for crop growth will assist conservationists and decision-makers in planning for climate change.

Location: South Africa.

Methods: We modelled climatic suitability in 2055 for maize and wheat cultivation, two extensively planted, staple crops, and overlaid projected changes with PAs and PA expansion priorities.

Results: Changes in winter climate could make an additional 2 million ha of land suitable for wheat cultivation, while changes in summer climate could expand maize suitability by up to 3.5 million ha. Conversely, 3 million ha of lands currently suitable for wheat production are predicted to become climatically unsuitable, along with 13 million ha for maize. At least 328 of 834 (39\%) PAs are projected to be affected by altered wheat or maize suitability in their buffer zones.

Main conclusions: Reduced crop suitability and food scarcity in subsistence areas may lead to the exploitation of PAs for food and fuel. However, if reduced crop suitability leads to agricultural abandonment, this may afford opportunities for ecological restoration. Expanded crop suitability in PA buffer zones could lead to additional isolation of PAs if portions of newly suitable land are converted to agriculture. These results suggest that altered crop suitability will be widespread throughout South Africa, including within and around lands identified as conservation priorities. Assessing how climate change will affect crop suitability near PAs is a first step towards proactively identifying potential conflicts between human adaptation and conservation planning.

\section{Keywords}

Adaptation, climate change, crop suitability, indirect impacts, maize, South Africa, species distribution modelling, wheat.

\section{INTRODUCTION}

Climate change directly threatens a significant fraction of the Earth's species. Changing precipitation and temperature condi- tions likely will alter the geographical ranges of species and may drive many to extinction (Parmesan \& Yohe, 2003; Thomas et al., 2004). Climate change is also likely to trigger a wide range of secondary impacts, whereby efforts by people to mitigate and 
adapt to climate change further compromise natural ecosystems. Secondary impacts have already been observed or projected for several large-scale projects aimed at the mitigation of climate change (Paterson et al., 2008). For example, the recent push for biofuels has resulted in agricultural expansion and corresponding loss of ecosystems (Wilson et al., 2008).

Of potentially greater consequence to biodiversity conservation are secondary impacts resulting from human adaptation to climate change (Turner et al., 2010). Because the effects of climate change have only begun to be felt, human adaptive responses have thus far been limited in scope and scale. Hence, the conservation community has not dealt with, and is largely unprepared for, the increased pressures to biodiversity that will result from human adaptation. However, historical examples of the ways in which societies have responded to shifting climate conditions suggest that the impacts of human adaptation could pose substantial risks for ecological conservation (Turner et al., 2010).

A major threat to ecosystems stemming from human adaptation is changes in the distribution of lands suitable for agriculture. Agricultural development is a well-known driver of habitat loss (Foley et al., 2005; Gibbs et al., 2010), and change in productivity because of climate change will prompt agricultural expansion in some areas accompanied by contraction in others. For example, rising temperatures are projected to increase crop suitability at higher latitudes (Ramankutty et al., 2002). Conversely, agricultural productivity in the tropics and many developing countries is projected to decrease (Ramankutty et al., 2002; Lobell et al., 2008), which will also affect conservation (both positively and negatively), depending on how individuals and societies respond.

Although there are many factors that shape human decisions to cultivate crops, including market forces and socio-political drivers, climatic suitability clearly plays an important role. Altered crop yield may prompt farmers to intensify crop production, alter management practices, expand into new areas or abandon existing farms. All of these actions have ecological consequences, including changing habitat quality, altering landscape connectivity or changing land values and the associated costs of land acquisition (Henle et al., 2008).

Projecting the second-order impacts of climate change for ecological conservation inherently involves assessing human decision-making. As such, the problem crosses numerous disciplinary boundaries. In this study, we address only the physical science component, with a goal of identifying the potential magnitude of the impact on biodiversity conservation if agricultural zones were fully shifted in response to climate change. We use species distribution models to project changes in climatic suitability for non-irrigated wheat and maize in South Africa. We measure the degree to which altered crop productivity will overlap existing protected areas (PAs) and PA expansion priorities and/or create restoration opportunities within existing agricultural matrices. The types of conflicts and opportunities - forecast here are likely to arise in many parts of the world where agricultural lands and natural ecosystems commingle.

\section{BACKGROUND}

We focus on wheat and maize, two key crops in South Africa in terms of planted area and human consumption (Anonymous, 2009). Owing to water scarcity throughout the country, both of these crops are predominantly rain-fed [only about $10 \%$ of crops in South Africa are irrigated; (Byrnes, 1996)], making them susceptible to changes in climate. Maize is grown primarily in the summer rainfall zone (the central, northern and eastern portions of the country), between the months of October and July. Most of the production occurs in the provinces of North West, Free State and Mpumalanga (Fig. 1). Between 2000 and 2008, an average of 3,100,000 ha was planted with maize, producing nearly $10,000,000$ tons of the crop with an economic value $>10$ billion rand (\$US 1.4 billion) (Anonymous, 2009). The majority of maize is produced on large, commercial farms. However, smaller-scale subsistence farmers account for a growing percentage of the land cultivated for maize (Cousins \& Scoones, 2010).

In contrast, the bulk of South Africa's wheat is produced in large, commercial farms in the winter (May-December) in the south-western region of the country. This region corresponds primarily to the Western Cape Province (Fig. 1), where 55-80\% of precipitation falls between April and September. Between 2000 and 2008, an average of 820,000 ha was planted with wheat, producing 2,300,000 tons of the crop with an economic value $>3.5$ billion rand ( $\$$ US 500 million) (Anonymous, 2009).

We evaluate potential changes in crop suitability in the context of current and future overlap with priority areas for conservation. There are currently 597 formal statutory PAs in South Africa, encompassing over 8,000,000 ha, and an additional 237 informal conservation areas (including game reserves and private nature reserves) totalling 900,000 ha. PAs are managed for biological conservation, although many were not originally conserved with that aim in mind (e.g. many PAs were established to protect water catchments) (Anonymous, 2008). A recently completed systematic assessment of protected area expansion priorities (National Protected Area Expansion Strategy, or NPAES) was undertaken by a group including one of this paper's authors (S. Holness) for the National Department of Environmental Affairs and the South African National Biodiversity Institute (SANBI). This work identified a further 12,000,000 ha within 42 distinct ecosystems for priority PA expansion in order to meet national biodiversity conservation goals (Anonymous, 2008). We considered both existing PAs and NPAES expansion priorities when evaluating overlap with shifting crop suitability.

\section{METHODS}

\section{Data}

\section{Maize and wheat distributions}

Presence points for wheat and maize were derived from the Producer Independent Crop Estimate System (PICES) dataset 


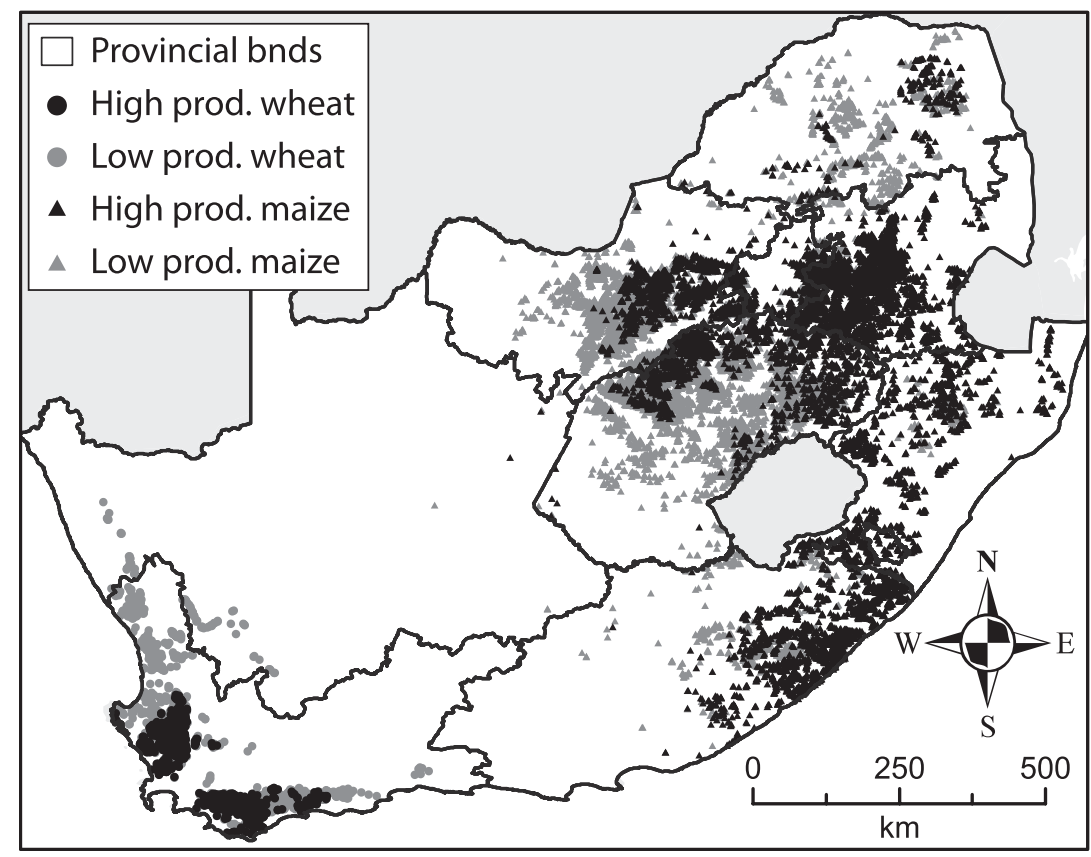

Figure 1 Current distribution of non-irrigated maize and wheat in South Africa based on the Producer Independent Crop Estimate System dataset (SIQ, 2007). Grey circles are winter wheat, with darker grey indicating higher-productivity cultivation (based on remote sensing; see Methods). Grey triangles are maize, with darker grey indicating higher-productivity cultivation.

(SIQ, 2007). PICES data identify the crop types growing within known crop fields (mapped using satellite imagery) between 2006 and 2009; these identifications were made by a trained observer in a light aircraft. Aerial surveys occurred during the months of peak crop growth (summer for maize and winter for wheat) and followed a geographically systematic sampling approach (SIQ, 2007). The PICES dataset also identifies irrigated crops.

Although the PICES crop data are reliable, in some cases points represented very small fields $(<1$ ha) with low productivity that were not representative of crop types being grown at the resolution of this study $\left(1 \mathrm{~km}^{2}\right)$. In order to select presence points that were representative of landscape scale growth patterns, we used time series of Normalized Difference Vegetation Index (NDVI) derived from the Moderate Resolution Imaging Spectroradiometer (MODIS) satellite at $1-\mathrm{km}$ resolution. First, we resampled presence points to a $1-\mathrm{km}$ spatial resolution to remove duplicate points within the same pixel. Next, we selected only those presence points displaying the appropriate growing season based on remote sensing. For wheat, we identified pixels with a winter growing season, while for maize we identified pixels with a summer growing season. We identified winter and summer growing seasons as pixels with $>0.10$ NDVI difference between February and August (for summer maize) and between August and January (for winter wheat).

Finally, in order to differentiate between high-productivity and low-productivity crops, which might provide further insight into climate requirements for productive non-irrigated agriculture, we divided each dataset in half based on average maximum NDVI between 2000 and 2008, creating equal numbers of crop presence points with high productivity (upper 50\%) and low productivity (lower 50\%). The distribution of wheat and maize points in South Africa is shown in Fig. 1.

\section{Environmental variables}

Climate variables used to build crop suitability models were derived from the South African quinary catchment database, which provides historical weather records from 1979 to 1999 for 5838 watersheds (mean area $=135 \mathrm{~km}^{2}$ ) in South Africa, Lesotho and Swaziland (Schulze \& Horan, 2010). Including terrain variables in addition to climate in distribution models has been shown to improve model fit (Austin \& Van Niel, 2011). We tested eight soil-related predictors: drained upper and lower limits for the top- and subsoil horizons, the differences between the drained upper and lower limits for the top- and subsoils (i.e. plant available water), total soil depth and topsoil organic carbon content. The first seven of these parameters were derived from the South African Land Type Memoirs (SIRI, 1987), mapped onto topographic landforms (catenal positions) with an average area of $46 \mathrm{~km}^{2}$. We derived topsoil organic carbon estimates at the same spatial resolution using regression kriging (Hengl et al., 2004) with 3377 soil profiles measured by the Agricultural Research Council and eight spatial predictors. Further details on the methods used to create the soils data can be found in the study by Estes et al. (2011).

Climate projections for 2046-2065 were derived from the IPCC 4th assessment Atmosphere Ocean General Circulation 
Models (AOGCMs). We used a total of nine climate models in the analysis: CCCMA-CGCM3.1, CNRM-cm3, CSIRO-mk3.5, GFDL-CM2.1, GFDL-CM2.0, IPSL-CM4, MIUB-ECHO-G, MPI-ECHAM5 and MRI-CGCM-2.3.2. We used climate projections from each AOGCM based on both the B1 and A2 emissions scenarios. The B1 scenario describes a world with increasing globalization coupled with the rapid development of alternative energy where atmospheric $\mathrm{CO}_{2}$ concentrations approach 550 p.p.m. by 2100 (Nakicenovic \& Swart, 2000). The A2 scenario describes a world of rapid population growth and regional economic growth where atmospheric $\mathrm{CO}_{2}$ concentrations approach 850 p.p.m. by 2100 (Nakicenovic \& Swart, 2000). We selected these two scenarios to illustrate both low (B1) and high (A2) degrees of climate change.

To improve the spatial resolution of our modelled future climate data, we downscaled each AOGCM scenario to the quinary catchment records using a technique based on selforganizing maps (Hewitson \& Crane, 2006). This approach classified unique climatic states defined by atmospheric predictors provided by the AOGCM (and the NCEP-DEO AMIP-II Reanalysis data provided by NOAA/OAR/ESRL PSD from http://www.esrl.noaa.gov/psd/, which was used to train the downscaling). We then constructed observed probability density functions of each variable to be downscaled (drawn from quinary catchment weather records) for each of the identified synoptic states. Twenty-year precipitation and temperature records were then constructed for the control (1979-1999) and future (2046-2065) time periods for each quinary catchment by stochastically resampling from the probability density functions. To calculate future climate conditions, we added the projected anomalies (found by subtracting current from future conditions for each AOGCM) to the baseline quinary catchment climate variables.

\section{Crop modelling approach}

One approach for modelling crop productivity uses detailed, process-based mechanistic models (e.g. DSSAT, Jones et al., 2003; APSIM, Keating et al., 2003). However, these models are data intensive and require detailed inputs describing, for example, soil water-holding and chemical properties at multiple depths, management practices (e.g. planting density, fertilization timing and amount) and daily climate data. These types of data are often collected for specific agricultural fields, which is the application for which they were originally designed. However, the information required by process-based models is rarely available spatially, has been interpolated at a coarse resolution (e.g. $1 / 4$ degree) or is of questionable quality because of limited data.

In order to produce model results at management-relevant spatial scales (in this case, $1-\mathrm{km}^{2}$ spatial resolution over a 1.2million $\mathrm{km}^{2}$ land area), we instead used a distribution modelling approach to project shifts in crop suitability. Empirical correlations between climate and crop yield have previously been used to estimate future risk to agricultural sectors (Lobell et al., 2008). Distribution modelling uses empirical relationships between abiotic variables (in this case, climate and slope) and current distribution to identify climatically suitable habitat (e.g. Franklin, 1995; Guisan \& Zimmermann, 2000; Pearson \& Dawson, 2003). Distribution models have been criticized for being too simplistic (Dormann, 2007), in particular because they neglect species interactions and population dispersal. However, agricultural communities are typically grown in monocultures and dispersed through deliberate cultivation. Our focus on rain-fed maize and wheat, meanwhile, means that these crops are not growing in climatically unsuitable regions, maintained by irrigation, which would introduce model bias (Thuiller et al., 2004). Further, comparative studies have shown that plant distributions projected by empirical distribution models are comparable to those generated by mechanistic models (Hijmans \& Graham, 2006). Hence, empirical distribution models should provide a reasonable characterization of the spatial distribution of current and future climate conditions needed by the two crops.

\section{Current climatic suitability}

Distribution models for wheat and maize were created using maximum entropy (MAXENT; Phillips et al., 2006), which applies simple functions to each environmental variable relative to crop presence points. The MAXENT model was selected because it is commonly used by conservation scientists and practitioners and performs well when compared with other distribution (Elith et al., 2006) and mechanistic (Hijmans \& Graham, 2006) models.

We used cumulative precipitation, maximum and minimum temperatures during each crops' growing season as climatic predictor variables. These climatic predictors were selected based on crop physiology. We supplemented these predictors with soils data, but added soil predictors based on their contribution to the MAXENT model. We selected the best model by dividing the maize and wheat datasets into $80 \%$ training and $20 \%$ testing. We defined climatically suitable for cultivation by identifying the model thresholds that encompassed 95\% of training occurrences. Following Warren \& Seifert (2011), we then chose the set of climate + soils predictor variables that minimized the difference in overall map accuracy of the testing-training suitability maps. Overall map accuracy was calculated using the average of (1) fraction of occurrence points correctly predicted, and (2) 1 - fraction of total land area predicted, where total land area was the country of South Africa. Minimizing the difference in the accuracy of testingtraining achieves a balanced model that is neither oversimplistic nor overcomplex and is effective for approximating suitable habitat with large distribution datasets (Warren \& Seifert, 2011).

\section{Future climatic suitability}

We used MAXENT and the same set of predictor variables to create maps of future climatic suitability based on the AOGCM projections scaled to the quinary catchments. In addition to 
precipitation and temperature changes projected by the AOGCMs, we built in an assumption of increased plant water-use efficiency because of increasing atmospheric $\mathrm{CO}_{2}$ concentrations. Based on the changes in crop water-use efficiency associated with $\mathrm{CO}_{2}$ rise in free-air $\mathrm{CO}_{2}$ enrichment (FACE), we assumed a $5 \%$ increase in wheat water-use efficiency (Hunsaker et al., 2000) and a 10\% increase in maize water-use efficiency (Leakey et al., 2009), which we incorporated by increasing AOGCM projected precipitation variables used in MAXENT. We did not include any changes in suitability associated with direct $\mathrm{CO}_{2}$ uptake for photosynthesis owing to uncertainties in the magnitude of that effect (Long et al., 2006), although C3 crops (e.g. wheat, but not maize) will likely become more productive with rising atmospheric $\mathrm{CO}_{2}$.

Projections of climatic suitability for wheat and for maize based on each individual AOGCM were summed together to create a model ensemble with values ranging from zero (none of the AOGCMs project climatic suitability) to nine (all of the AOGCMs project climatic suitability) (Araujo \& New, 2007). This type of ensemble approach identifies the degree of overlap amongst the models of future crop suitability, which can inform how much confidence is assigned to projected change at a given location. For the purpose of calculating changes in land area and overlap with PAs, we defined future suitability as any pixel projected as suitable in 2050 by two or more AOGCMs and unsuitable as any pixel projected as suitable by less than two AOGCMs (See Appendix S1 in Supporting Information for sensitivity analysis of ensemble model thresholds). This threshold will tend to err on the side of overpredicting future crop suitability (and underpredicting unsuitability), but model ensemble values (between 2 and 9) can ultimately be used to inform the likelihood of future suitability.

We identified both expansion and contraction of climatically suitable land area for maize and wheat. We overlaid areas that gained crop suitability with NPAES expansion priorities, as well as lands within a $10-\mathrm{km}$ buffer surrounding existing PAs, and calculated overlapping land area for wheat and maize using both the B1 and A2 emissions scenarios. We also overlaid areas that lost crop suitability with NPAES expansion priorities and PA buffers. However, in the lost suitability case, land area also had to be within an existing agricultural matrix (defined as $<10 \mathrm{~km}$ from current cultivation). In order to compare potential future expansion of croplands to current patterns of cultivation, we also calculated the area of existing crop fields with NPAES and PA buffers. Existing crop fields data were based on field boundaries manually digitized from satellite data by Geo Terra Image (GTI, 2008).

\section{RESULTS}

\section{Maize and wheat distributions}

The original PICES dataset consisted of 6362 points of nonirrigated wheat cultivation and 29,287 points of non-irrigated maize. The removal of duplicate points within a 1-km MODIS pixel reduced those numbers to 4664 wheat points and 21,209 maize points. The final criterion of winter (for wheat) and summer (for maize) phenologies with amplitudes $>0.10$ NDVI further reduced the datasets to a final set of 2119 wheat presence points and 20,210 maize presence points (Fig. 1).

Crop fields in South Africa currently cover over 13 million ha (GTI, 2008). The majority are maize or wheat cultivation, but this number also includes secondary crops (fruits, vegetables, viticulture, sugarcane). Crop fields currently overlap 2.6 million ha of PA buffers (10\% of total buffer area) and 270,000 ha of NPAES expansion priorities (2\% of total NPAES area).

\section{Current climatic suitability}

Environmental variables used to construct the maize and wheat models are presented in Table 1, along with their mean value and standard deviation across all crop occurrence points. Land areas suitable for maize cultivation based on current climate conditions are widely distributed across the north-eastern provinces in South Africa (Fig. 2). The area under the curve (AUC) statistic for the maize model is 0.895 . Overall map accuracy based on the testing dataset was 0.80 . Land area currently climatically suitable for maize cultivation totals over 40 million ha ( 9 million ha of this suitable area currently contains crop fields; GTI, 2008). High-productivity maize has a very similar distribution to all maize, except for some reduced climatic suitability to the west as conditions become increasingly arid.

Land areas suitable for wheat cultivation are concentrated primarily in the Western Cape Province (Fig. 2). AUC for the wheat model is 0.985 . Overall map accuracy based on the testing dataset was 0.95 . Land area currently climatically suitable for wheat cultivation totals over 5.5 million ha (over 1.7 million ha of this suitable area currently contains crop fields; GTI, 2008). High-productivity wheat distribution is considerably different from all wheat. High-productivity wheat is concentrated in the Agulhas Plain along the south coast and Swartland along the west coast. Land area currently climatically suitable for high-productivity wheat totals over 1.9 million ha ( 1 million ha of this suitable area currently contains crop fields; GTI, 2008). Wheat suitability declines as conditions become drier to the north and as soil conditions are less favourable at higher elevations.

\section{Future climatic suitability}

There are currently 597 formal reserves in South Africa, plus an additional 237 informal conservation areas (mainly game reserves and private nature reserves). The $10-\mathrm{km}$ buffer zones surrounding between 232 and $254(39-43 \%)^{1}$ of formal and 96-107 (40-45\%) of informal reserves are projected to have altered wheat or maize suitability. That is, at least $40 \%$ of PA

\footnotetext{
${ }^{1}$ Ranges in land area presented in this section depend on the emissions scenario (B1 or A2) used in the models. Figures of A2 model results are presented in supplementary materials.
} 


\section{B. A. Bradley et al.}

Table 1 Predictor variables used to construct models for maize and wheat based on crop physiology, including the mean value and standard deviation across all presence points. Predictor variables are presented in order of importance based on MAXENT predictor gain.

\begin{tabular}{lcc}
\hline Predictor variables used for maize & Mean value & Standard deviation \\
\hline Growing season precipitation (October-April) & $551 \mathrm{~mm}$ & $122 \mathrm{~mm}$ \\
Growing season maximum temp (January) & $28.5{ }^{\circ} \mathrm{C}$ & $2.1^{\circ} \mathrm{C}$ \\
Soil depth & $73 \mathrm{~cm}$ & $27 \mathrm{~cm}$ \\
Growing season minimum temp (April) & $9.4{ }^{\circ} \mathrm{C}$ & $2.1^{\circ} \mathrm{C}$ \\
Topsoil organic carbon & $0.79 \%$ & $0.66 \%$ \\
Predictor variables used for wheat & Mean Value & Standard deviation \\
\hline Growing season precipitation (May-September) & $263 \mathrm{~mm}$ & $112 \mathrm{~mm}$ \\
Growing season minimum temp (August) & $7.2^{\circ} \mathrm{C}$ & $1.0^{\circ} \mathrm{C}$ \\
Topsoil organic carbon & $0.67 \%$ & $0.38 \%$ \\
Growing season maximum temp (May-September) & $19.4{ }^{\circ} \mathrm{C}$ & $1.1^{\circ} \mathrm{C}$ \\
\hline
\end{tabular}
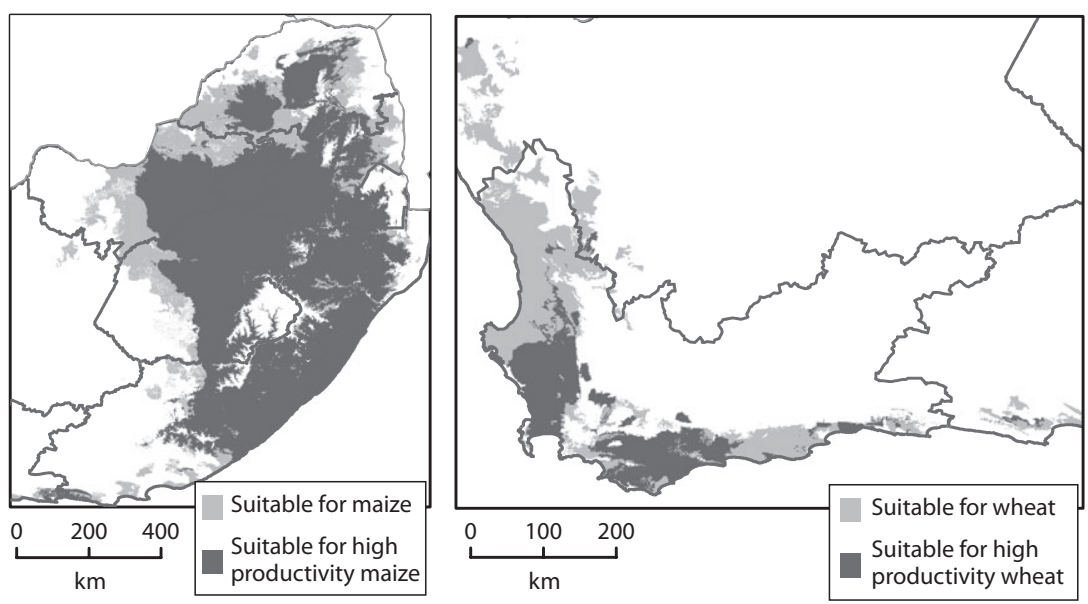

Figure 2 Current climatic suitability for maize and wheat cultivation based on MAXENT models constructed from current non-irrigated crop distributions. buffer zones will either gain crop suitability or lose crop suitability within existing agricultural matrices $(10 \mathrm{~km}$ from current agriculture).

Loss of climatic suitability for maize is projected to be most extensive along the northern and western edges of its current distribution (Fig. 3; Appendix S2). These lands are semi-arid, and it is likely that water limitation is the primary cause. Between 12 and 15 million ha are projected to lose climatic suitability for maize production, representing up to $37 \%$ of currently suitable land area. Maize suitability is most likely to expand into higher elevation areas such as those along the eastern edges of Mpumalanga and Free State and the interior of Eastern Cape. Projected gains in climatic suitability for maize production total between 3.5 and 3.8 million ha (Fig. 3; Appendix S2). There was no substantive difference in the projections for maize suitability using the subset of high maize productivity, so we presented only results from models using all maize points here.

The area of increased maize suitability overlaps buffer zones surrounding 132-135 PAs (out of a total 221 PAs currently within the maize-growing region), including nature reserves, game reserves, national parks and state forests. Maize suitability gains in PA buffer zones total between 960,000 and
980,000 ha, with the most overlap occurring in Limpopo and Eastern Cape provinces. Increased maize suitability also overlaps 540,000-560,000 ha of NPAES expansion priority sites, primarily in the northern portion of the Eastern Cape Province (Figs. 3b,c; Appendix S2B,C).

Decreased maize suitability within current agriculture matrices overlaps buffer zones surrounding between 70 and 91 PAs. Maize suitability losses in buffer zones total between 1.3 and 1.7 million ha, with the largest blocks of overlap occurring in game reserves and nature reserves in Limpopo and North West provinces. Decreased maize suitability overlaps 260,000-410,000 ha of NPAES expansion priority sites throughout the maize-growing region. An example in western Free State is shown in Fig. 3d and Appendix S2D.

Loss of climatic suitability for wheat occurs primarily along the west coast of the Western Cape Province (Fig. 4; Appendix S3). Temperatures along the coasts are higher than inland and higher temperatures are the primary cause for reduced wheat suitability. Between 2.6 and 3.4 million ha (48-62\%) of currently suitable land area are projected to lose climatic suitability. However, wheat suitability is also likely to expand substantially into slightly higher elevations as well as inland into areas that are currently cooler and/or drier than existing 
Figure 3 Changes in climatic suitability for non-irrigated maize in South Africa based on the B1 emissions scenario. (a) Within areas currently suitable for maize cultivation, climatic conditions are projected to become less suitable (dark blue) in parts of North West, the Free State and Limpopo provinces. Climatic conditions are projected to become newly favourable for maize cultivation (hashed areas) in the northern portions of Mpumalanga and Eastern Cape provinces. Colours correspond to the number of models in agreement about future suitability. (b) Projected gains and losses in climatic suitability for maize (based on a threshold of two overlapping models) compared to PAs and National Protected Area Expansion Strategy (NPAES) expansion priorities (vertical and horizontal green hashes, respectively). (c) Example of increased climatic suitability for maize surrounding NPAES expansion priorities. (d) Example of decreased climatic suitability for maize surrounding PAs and NPAES expansion priorities currently within an agricultural matrix. (a)

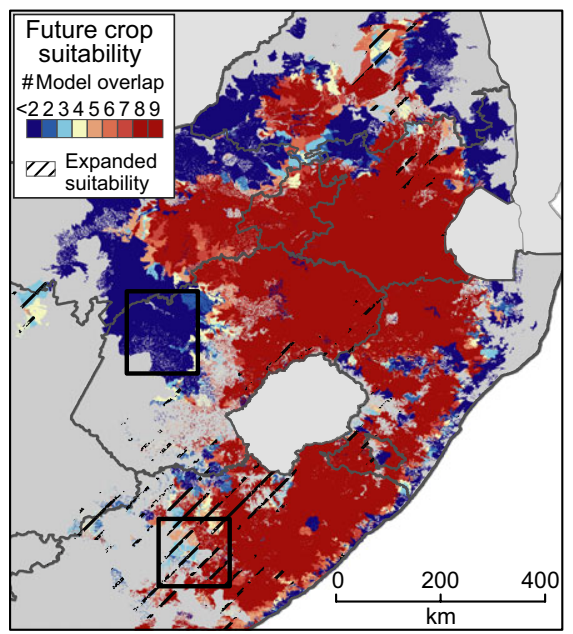

(b)

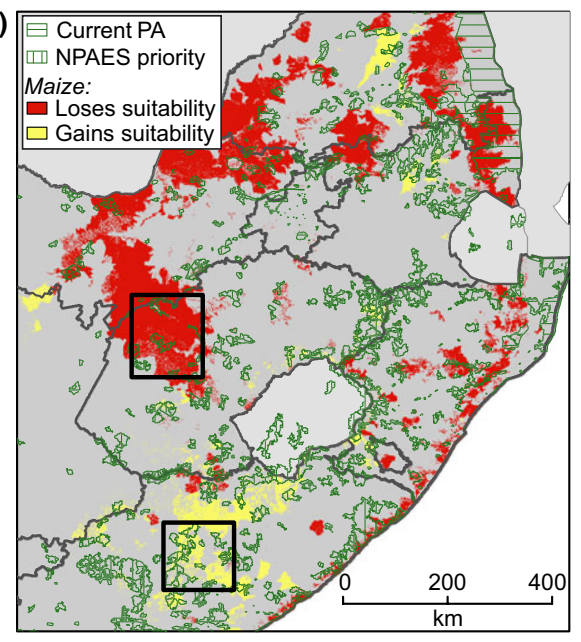

(c)

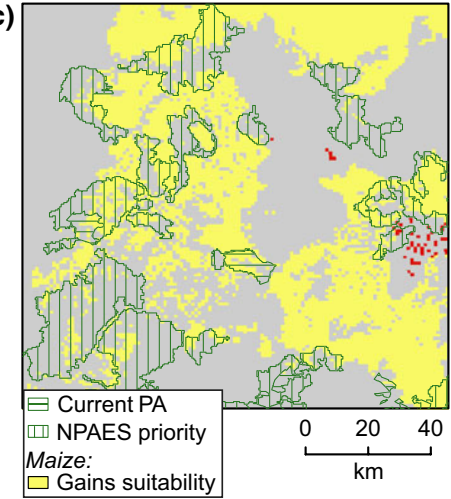

(d)

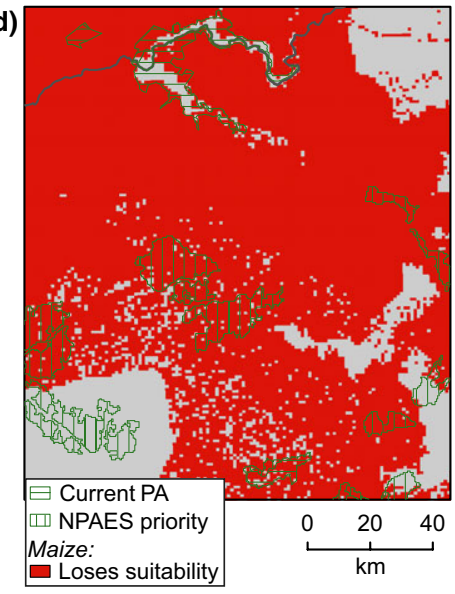

cultivated lands. Projected gains in climatic suitability for wheat production total 2.2 million ha in both scenarios, a potential $40 \%$ expansion relative to current suitability, offsetting some of the losses elsewhere.

The area of increased wheat suitability overlaps buffer zones surrounding 88-94 PAs (out of a total 166 PAs currently within the wheat growing region), primarily nature reserves, national parks and protected water catchments. Wheat suitability gains within PA buffer zones total between 860,000 and 960,000 ha, with the majority of overlap occurring in upland areas of interior Western Cape. Increased wheat suitability overlaps 450,000-500,000 ha of NPAES expansion priority sites, along the border of Western Cape and Northern Cape provinces and in the interior of the Western Cape (Fig. 4c; Appendix S3C).

The area of decreased wheat suitability within current agriculture matrices overlaps buffer zones surrounding 72-83 PAs. Wheat suitability losses in PA buffer zones total between 640,000 and 760,000 ha, with the largest blocks of overlap occurring around reserves on the west coast (Fig. 4d; Appendix S3D). A further 80,000-90,000 ha of NPAES expansion priorities exist in areas likely to lose wheat crop suitability, including several expansion priorities along the south coast.
Changing climatic suitability also affects high-productivity wheat. Loss of climatic suitability for high-productivity wheat is projected across broad portions of the west coast, including the bulk of heavily cultivated Swartland (Fig. 5; Appendix S4). Decreased suitability totals between 1.6 and 1.8 million ha, or $81-93 \%$ of current high-productivity wheat. Although many of these areas remain suitable for wheat production (Fig. 4; Appendix S3), reductions in climatic suitability could substantially reduce crop output. Increased suitability for high-productivity wheat totals only between 300,000 and 430,000 ha.

Increased high-productivity wheat suitability overlaps buffer zones surrounding 36-41 PAs. Overlap areas total between 170,000 and 240,000 ha. High-productivity wheat suitability gains overlap an additional $60,000-100,000$ ha of NPAES expansion priorities. The area of decreased high-productivity wheat suitability within current agriculture matrices overlaps the buffer zones of 54-64 PAs and overlaps a total of 40,00050,000 ha of NPAES expansion priority sites.

\section{DISCUSSION}

Demand for cereal crops globally is likely to continue to increase because of population growth, changing diets and 


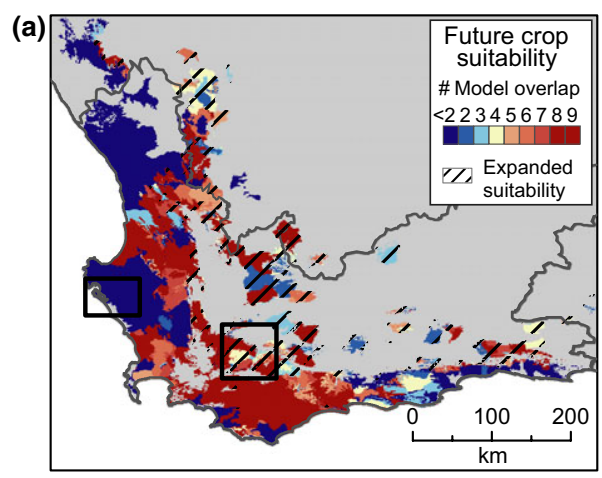

(b)

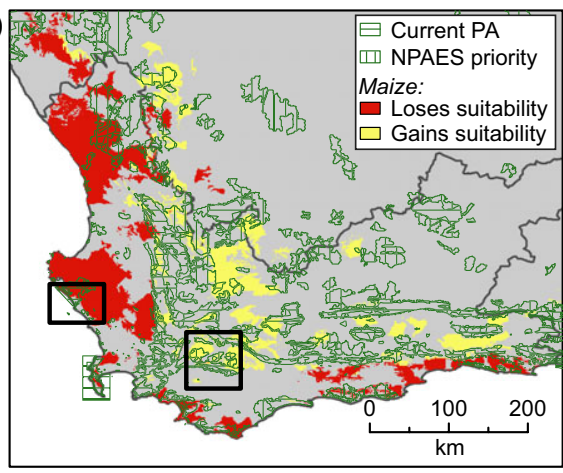

(c)

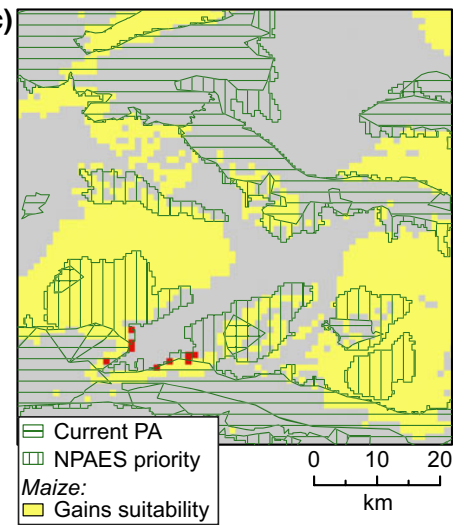

(d)

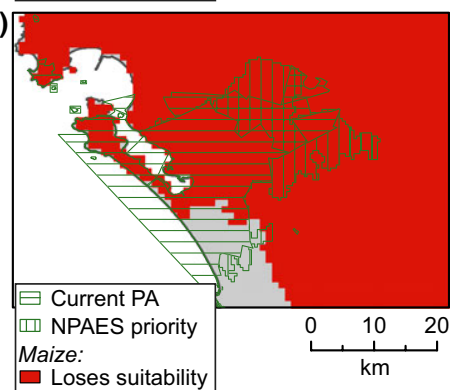

Figure 4 Changes in climatic suitability for non-irrigated wheat in South Africa based on the B1 emissions scenario. (a) Climate conditions are projected to become less suitable for winter wheat (dark blue) along the coasts and increasingly suitable for winter wheat inland at slightly higher elevation (hashed areas). Colours correspond to the number of models in agreement about future suitability. (b) Areas of overlap between changing wheat suitability (based on a threshold of two overlapping models) with PAs and National Protected Area Expansion Strategy (NPAES) expansion priorities (vertical and horizontal green hashes, respectively). (c) Example of increased climatic suitability for wheat surrounding PAs and NPAES expansion priorities. (d) Example of decreased climatic suitability for wheat surrounding a conservation priority. expansion of biofuels (Alexandratos, 1999; Escobar et al., 2009). Although increasing crop yield may offset some of the future demand (Olmstead \& Rhode, 2011), it is unlikely to satisfy all of it (Ziska, in press). Hence, extensification of crop fields is needed to satisfy population and development trends alone, and climate change will likely increase this need (Turner et al., 2010). How shifts in agricultural suitability because of climate change influence biodiversity conservation at national and local scales will depend upon choices made by individuals, commercial enterprises and policy makers in response to changes in cropland productivity. Climate change is likely to shift the distribution of lands climatically suitable for agriculture. In some cases, changing cropland productivity could threaten biodiversity and complicate conservation actions if farmers choose to expand cultivation into newly suitable areas. In other cases, opportunities for restoration or acquisition of remaining natural ecosystems may emerge as existing croplands become less suitable. By anticipating potential areas of conflict as well as opportunities for restoration and land acquisition, conservation planners can better identify and resolve pressures arising from human adaptation to climate change (Table 2).

Our results suggest that changes in crop suitability will substantively affect existing and planned reserves in South Africa. At least $40 \%$ of all formal and informal reserves are projected to have altered crop suitability within their buffer zones. Even if socio-political and economic forces lead to only a fraction of this potential being realized, the magnitude of this threat indicates that the secondary impacts of climate change adaptation must be considered in conservation planning.
In addition to threats from agricultural expansion, native species also face direct threats from climate change. As a result, projections of the impacts of climate change on native species (e.g. Midgley et al., 2002) and the efficacy of reserve networks (e.g. Coetzee et al., 2009) should certainly be considered when assessing overall risk to biodiversity. Because we aimed to assess the magnitude of risk posed by secondary impacts, we assume that PAs and NPAES expansion priorities will retain enough species of concern to remain targets for conservation action.

\section{Conservation threats because of increased crop suitability}

Expansion of suitable cropland in South Africa because of climate change is projected to occur primarily in areas that are slightly cooler than currently cultivated areas, often at higher elevations. Owing to the low threshold used to estimate future crop suitability (two or more AOGCM projections), it is likely that some of the projected expansion areas will ultimately not be appropriate for wheat or maize cultivation. Areas projected by most or all of the AOGCMs to become suitable for crops (orange and red areas in panel a of Figs 3-5; Appendix S2-S4) are more likely to become climatically suitable. These areas can be winnowed down further by taking into consideration local factors such as soil quality, terrain and access to markets, which will decrease the amount of land truly suitable for agriculture. Finally, human decision-making based on economic and socio-political factors may be more important than crop suitability for creating conflicts with ecological conservation. Hence, input from the social sciences is needed to fully assess risk. 
(a)

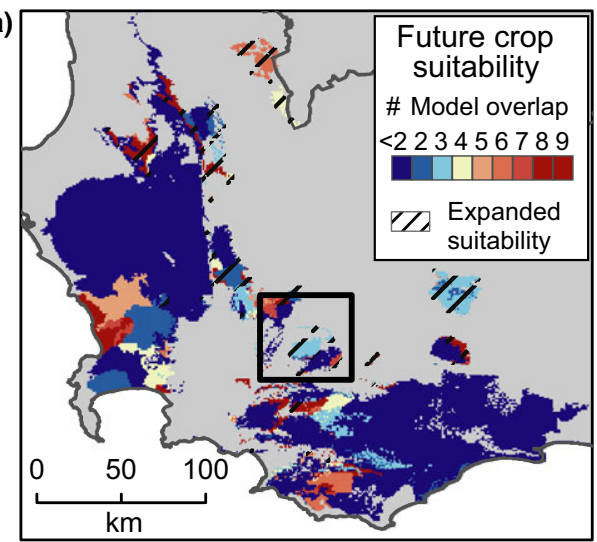

(b)

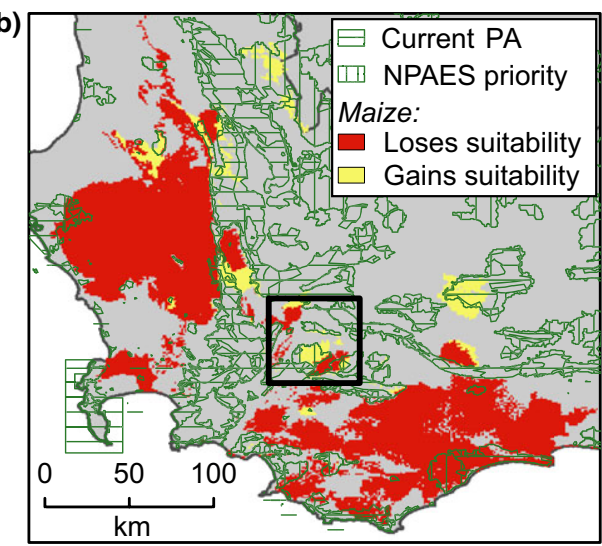

(c)

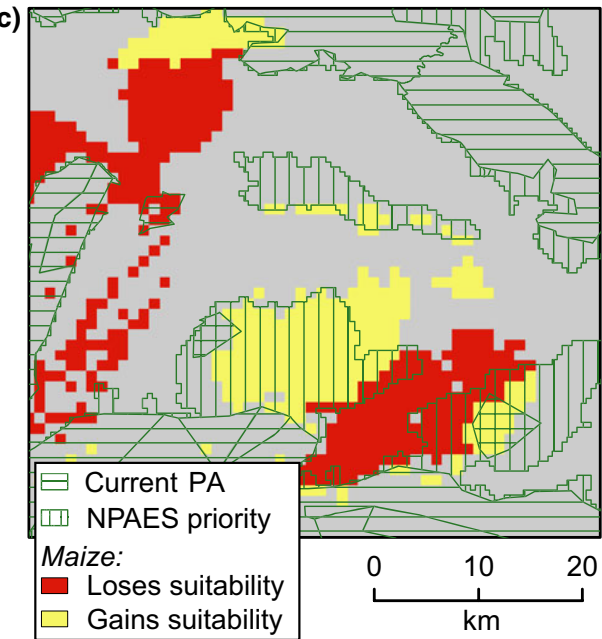

Figure 5 Changes in climatic suitability for non-irrigated, high-productivity wheat based on the B1 emissions scenario. (a) Climate conditions are projected to become less suitable for high-productivity wheat in Swartland (dark blue) and increasingly suitable for high-productivity wheat inland at slightly higher elevation (hashed areas). Colours correspond to the number of models in agreement about future suitability. (b) Areas of overlap between changing high-productivity wheat suitability (based on a threshold of two overlapping models) with PAs and National Protected Area Expansion Strategy (NPAES) expansion priorities (vertical and horizontal green hashes, respectively). (c) Example of gained and lost suitability for high-productivity wheat surrounding PAs and NPAES expansion priorities.
Despite these caveats, it is likely that up to 1 million ha within NPAES expansion priorities and up to 2 million ha in PA buffer zones will become increasingly suitable for maize or wheat cultivation (yellow areas in panel b of Figs 3-5). If crop fields were to expand into all climatically suitable range, the addition of 1 million ha of cultivation in NPAES expansion priorities would represent a $400 \%$ increase relative to current crop field extents (270,000 ha). The addition of 2 million ha of crop fields in PA buffer zones would represent a 75\% increase relative to current crop field extents (2.6 million ha). Within NPAES expansion priorities, increased competition for land and associated rises in land prices could reduce the ability of government and private conservation organizations to acquire priority areas. Increased crop suitability adjacent to existing PAs is likely to affect land prices similarly, while intensified agricultural development in buffer regions could make PAs increasingly isolated.

In areas where food security is already a problem (primarily within former apartheid 'homelands' in the maize-growing region; Rose \& Charlton, 2002), increased climatic suitability may lead to farmers encroaching into PAs and buffers. Increased climatic suitability for maize is likely in the Eastern Cape and Mpumalanga provinces. This area also contains a number of PAs and NPAES expansion priorities (Fig. 3c). An increase in smallscale illegal farming could result in the fragmentation of remaining natural ecosystems, primarily within the grassland biome. For example, South African grasslands, which are poorly protected and found primarily in maize-dominated agricultural zones (Neke \& Du Plessis, 2004), could be increasingly threatened if maize suitability increases.

Lands suitable for wheat cultivation in the Western Cape could expand by upwards of 2.2 million ha (Fig. 4). Of the lands that gain suitability, over half are within PA buffers or NPAES expansion priorities, primarily within the Fynbos or Succulent Karoo biomes. Commercial farmers are likely to have the economic means to expand or intensify cultivation on newly suitable land. Several areas are likely to become climatically similar to current highly productive wheat fields, making them especially desirable for cropland expansion (Fig. 5c). In the Western Cape, where much of the land is already being farmed, increased suitability could lead farmers to convert remaining uncultivated lands that are currently marginal (e.g. owing to steeper slopes) to wheat cultivation. Conversion of marginal lands in the Western Cape threatens the few remaining patches of Renosterveld, one of the most threatened and heavily transformed ecosystems in the Cape Floristic Region and home to numerous endangered species (Kemper et al., 1999).

\section{Conservation threats because of decreased crop suitability}

Commercial and subsistence farmers across South Africa are likely to experience an overall reduction of cultivatable land because of climate change (Figs 4 and 5). The average change in wheat suitability across the B1 and A2 scenarios is a net 


\section{B. A. Bradley et al.}

Table 2 Changes in agriculture and potential consequences for biodiversity conservation.

\begin{tabular}{|c|c|}
\hline Change & Consequence \\
\hline \multicolumn{2}{|l|}{ Agriculture suitability increases } \\
\hline Generally & $\begin{array}{l}\text { Expansion of cropland could lead to habitat fragmentation, reduced connectivity and introduction of } \\
\text { invasive species } \\
\text { Expansion of cropland into new areas could increase threats to a range of species and habitats, creating } \\
\text { new urgent conservation priorities and increasing the burden on conservation resources }\end{array}$ \\
\hline In situ & $\begin{array}{l}\text { Conversion of native ecosystems in marginal lands to crops if prices increase } \\
\text { Agricultural intensification owing to economic benefits } \\
\text { Reduced need for agricultural expansion }\end{array}$ \\
\hline $\begin{array}{l}\text { Adjacent to and within } \\
\text { protected areas }\end{array}$ & $\begin{array}{l}\text { Reserve isolation owing to agricultural development in buffer areas } \\
\text { Social pressure to open protected areas to farming to avoid food scarcity } \\
\text { Illegal subsistence farming }\end{array}$ \\
\hline In PA expansion priorities & $\begin{array}{l}\text { Increased demand for land could trigger rising land prices and lesser land acquisition for conservation } \\
\text { Loss of expansion opportunities as land is transformed }\end{array}$ \\
\hline \multicolumn{2}{|l|}{ Agricultural suitability decreases } \\
\hline In situ & $\begin{array}{l}\text { Improved management practices and adoption of new agricultural technologies could mitigate crop loss } \\
\text { Increased use of fertilizers in response to crop loss could threaten surrounding native ecosystems } \\
\text { Diversion of water resources could threaten riparian habitat } \\
\text { Agriculture abandonment creates restoration opportunities }\end{array}$ \\
\hline Adjacent to protected areas & $\begin{array}{l}\text { Increased human dependence on natural resources (e.g. fuel wood, bush meat) threatens protected } \\
\text { ecosystems }\end{array}$ \\
\hline In PA expansion priorities & $\begin{array}{l}\text { Decreased demand for land could trigger declines in land prices and greater land acquisition for } \\
\text { conservation }\end{array}$ \\
\hline
\end{tabular}

PA, protected areas.

loss of 800,000 ha, or $14 \%$ of current suitable area. Although we modelled suitability for crop production rather than crop productivity, this projection corresponds well to previous estimates of $15 \%$ losses in wheat production in southern Africa by 2030 (Lobell et al., 2008). The average change in maize suitability across the B1 and A2 scenarios is a net loss of 9.8 million ha, or $24 \%$ of current suitable area. This projection also compares well to previous estimates of $30 \%$ losses in maize production in southern Africa by 2030 (Lobell et al., 2008). At a national level, climate change is likely to make it increasingly difficult for South Africa to meet its domestic food needs.

In regions dominated by subsistence farmers, who are less able to adopt technologies that might maintain crop productivity, decreasing crop yields could result in food scarcity. Food scarcity, in turn, may create new pressures on PAs and, in extreme cases, unstable social conditions not conducive to conservation. Communities with insecure food sources might seek additional farmland to make up for lost production (e.g. in marginal lands or PAs) and/or become more dependent on surrounding natural resources. For example, farming households may make increasing use of fuel and food resources within native ecosystems, harvesting wood and wild game (bush meat) to replace lost income (Brashares et al., 2004).

Commercial farmers will have greater access to infrastructure and technological resources (e.g. irrigation, drought resistant cultivars, fertilizers) that may allow them to maintain current levels of crop production even where climatic suitability decreases. This scenario is possible in the coastal portions of the Western Cape wheat belt (Figs 4d and $5 \mathrm{~d}$ ) and in areas of commercial maize cultivation in central Free State (Fig. 3). However, some of these compensatory practices could be detrimental to ecosystems (e.g. increased fertilizer run-off), while others may not be feasible [e.g. consistent irrigation in areas with periodic water shortages such as the Western Cape; (Muller et al., 2009)].

\section{Minimizing risk, maximizing opportunities}

Although human adaptation to decreased crop productivity may increase pressure on some protected lands, diminished crop potential or cropland abandonment could also provide conservation opportunities. Declining suitability in current croplands could lower surrounding land prices, making it more affordable for government or non-governmental organizations to acquire priority areas for conservation management (Pence et al., 2003; Anonymous, 2008) assuming these areas are able to retain their key species in the face of climate change. Restoration of cropland to native habitat could support important conservation goals, including reducing pressure from non-native species and increasing connectivity between patches of rare ecosystems (e.g. the Renosterveld in the Western Cape; Krug \& Krug, 2007). Of course, the success of such efforts will depend on the extent to which conservation objectives can be met in areas of decreased agricultural suitability. Our analysis suggests that these opportunities exist; multiple locations within the Agulhas Plain, for 
example, are critical to dispersal of Cape Proteaceae (Phillips et al., 2008), and several of these are currently under wheat cultivation but likely to lose crop suitability with climate change (Fig. 4d).

The distribution of areas of potential crop expansion, such as those projected for wheat in the Western Cape, could inform PA acquisition. Lands that are projected to become increasingly suitable for crops may become more expensive and thus difficult to acquire in future. These areas could be considered a high priority for acquisition now in order to ensure that an efficient and representative reserve network is created before they are either fragmented by agricultural activities or become prohibitively expensive. On the other hand, NPAES expansion priorities that overlap increased crop suitability also represent potential long-term conflicts with farmers and thus should be targeted only where very important for biodiversity.

\section{CONCLUSIONS}

The results presented here provide a broad, national view of potential changes to crop suitability in relation to PAs. Climate change plays an important role in human decision-making (Turner et al., 2010), and hence, shifts in cultivated areas could pose a serious threat to conservation efforts. It is likely that the threats and opportunities summarized in Table 2 are relevant for many areas where conservation and agriculture priorities intersect. Without better projections of human adaptive responses to climate change, conservationists and decisionmakers run the risk of overlooking a major, emerging threat to biodiversity.

\section{ACKNOWLEDGEMENTS}

We gratefully acknowledge funding from the Princeton Environmental Institute's Grand Challenges Program. We thank Anneliza Collet and Rona Beukes of the National Department of Agriculture, Terry Newby and Dave Turner of the Agricultural Research Council, Fanie Ferreira and Mark Thompson of GeoTerraImage and Eugene du Preez of SiQ for providing data used in developing models. Three anonymous reviewers provided suggestions that greatly improved this manuscript.

\section{REFERENCES}

Alexandratos, N. (1999) World food and agriculture: outlook for the medium and longer term. Proceedings of the National Academy of Sciences United States of America, 96, 5908-5914.

Anonymous. (2008) The National Protected Area expansion strategy 2008-2012: a framework for implementation. South African National Biodiversity Institute; National Department of Environmental Affairs and Tourism.

Anonymous. (2009) Abstractofagriculturalstatistics.p.115. South African Department of Agriculture, Pretoria, South Africa.
Araujo, M.B. \& New, M. (2007) Ensemble forecasting of species distributions. Trends in Ecology \& Evolution, 22, 42-47. Austin, M.P. \& Van Niel, K.P. (2011) Impact of landscape predictors on climate change modelling of species distributions: a case study with Eucalyptus fastigata in southern New South Wales, Australia. Journal of Biogeography, 38, 9-19.

Brashares, J.S., Arcese, P., Sam, M.K., Coppolillo, P.B., Sinclair, A.R.E. \& Balmford, A. (2004) Bushmeat hunting, wildlife declines, and fish supply in West Africa. Science, 306, 1180-1183.

Byrnes, R.M. (1996) South Africa: a Country Study. Federal Research Division, Library of Congress, Washington, DC. Available at: http://countrystudies.us/south-africa/ (accessed 1 May 2011)

Coetzee, B.W.T., Robertson, M.P., Erasmus, B.F.N., Van Rensburg, B.J. \& Thuiller, W. (2009) Ensemble models predict Important Bird Areas in southern Africa will become less effective for conserving endemic birds under climate change. Global Ecology and Biogeography, 18, 701-710.

Cousins, B. \& Scoones, I. (2010) Contested paradigms of 'viability' in redistributive land reform: perspectives from southern Africa. Journal of Peasant Studies, 37, 31-66.

Dormann, C.F. (2007) Promising the future? Global change projections of species distributions. Basic and Applied Ecology, 8, 387-397.

Elith, J., Graham, C.H., Anderson, R.P. et al. (2006) Novel methods improve prediction of species' distributions from occurrence data. Ecography, 29, 129-151.

Escobar, J.C., Lora, E.S., Venturini, O.J., Yanez, E.E., Castillo, E.F. \& Almazan, O. (2009) Biofuels: environment, technology and food security. Renewable \& Sustainable Energy Reviews, 13, 1275-1287.

Estes, L.D., Bradley, B.A., Beukes, H., Hole, D.G., Lau, M., Oppenheimer, M., Schulze, R., Tadross, M.A. \& Turner, W.R. (2011) Comparing mechanistic and empirical model projections of crop suitability and productivity: implications for projecting ecological change. In, Princeton, NJ.

Foley, J.A., Defries, R., Asner, G.P., Barford, C., Bonan, G., Carpenter, S.R., Chapin, F.S., Coe, M.T., Daily, G.C., Gibbs, H.K., Helkowski, J.H., Holloway, T., Howard, E.A., Kucharik, C.J., Monfreda, C., Patz, J.A., Prentice, I.C., Ramankutty, N. \& Snyder, P.K. (2005) Global consequences of land use. Science, 309, 570-574.

Franklin, J. (1995) Predictive vegetation mapping: geographic modelling of biospatial patterns in relation to environmental gradients. Progress in Physical Geography, 19, 474-499.

Gibbs, H.K., Ruesch, A.S., Achard, F., Clayton, M.K., Holmgren, P., Ramankutty, N. \& Foley, J.A. (2010) Tropical forests were the primary sources of new agricultural land in the 1980s and 1990s. Proceedings of the National Academy of Sciences United States of America, 107, 16732-16737.

GTI. (2008) Geo Terra Image: South African Crop Field Boundaries. In: National Crop Statistics Consortium Available at: http://www.geoterraimage.com (accessed 1 September 2009).

Guisan, A. \& Zimmermann, N.E. (2000) Predictive habitat distribution models in ecology. Ecological Modelling, 135, 147-186. 
Hengl, T., Heuvelink, G.B. \& Rossiter, D.G. (2004) A generic framework for spatial prediction of soil variables based on regression kriging. Geoderma, 120, 75-93.

Henle, K., Alard, D., Clitherow, J., Cobb, P., Firbank, L., Kull, T., Mccracken, D., Moritz, R.F.A., Niemela, J., Rebane, M., Wascher, D., Watt, A. \& Young, J. (2008) Identifying and managing the conflicts between agriculture and biodiversity conservation in Europe - a review. Agriculture Ecosystems \& Environment, 124, 60-71.

Hewitson, B.C. \& Crane, R.G. (2006) Consensus between GCM climate change projections with empirical downscaling: precipitation downscaling over South Africa. International Journal of Climatology, 26, 1315-1337.

Hijmans, R.J. \& Graham, C.H. (2006) The ability of climate envelope models to predict the effect of climate change on species distributions. Global Change Biology, 12, 2272-2281.

Hunsaker, D.J., Kimball, B.A., Pinter, P.J., Wall, G.W., Lamorte, R.L., Adamsen, F.J., Leavitt, S.W., Thompson, T.L., Matthias, A.D. \& Brooks, T.J. (2000) CO2 enrichment and soil nitrogen effects on wheat evapotranspiration and water use efficiency. Agricultural and Forest Meteorology, 104, 85105.

Jones, J.W., Hoogenboom, G., Porter, C.H., Boote, K.J., Batchelor, W.D., Hunt, L.A., Wilkens, P.W., Singh, U., Gijsman, A.J. \& Ritchie, J.T. (2003) The DSSAT cropping system model. European Journal of Agronomy, 18, 235-265.

Keating, B.A., Carberry, P.S., Hammer, G.L. et al. (2003) An overview of APSIM, a model designed for farming systems simulation. European Journal of Agronomy, 18, 267-288.

Kemper, J., Cowling, R.M. \& Richardson, D.M. (1999) Fragmentation of South African renosterveld shrublands: effects on plant community structure and conservation implications. Biological Conservation, 90, 103-111.

Krug, C.B. \& Krug, R.M. (2007) Restoration of old fields in Renosterveld: a case study in a Mediterranean-type shrubland of South Africa. Old fields: dynamics and restoration of abandoned famland (ed. by V.A. Cramer and R.J. Hobbs), pp. 265-285. Island Press, Washington, DC.

Leakey, A.D.B., Ainsworth, E.A., Bernacchi, C.J., Rogers, A., Long, S.P. \& Ort, D.R. (2009) Elevated CO2 effects on plant carbon, nitrogen, and water relations: six important lessons from FACE. Journal of Experimental Botany, 60, 2859-2876.

Lobell, D.B., Burke, M.B., Tebaldi, C., Mastrandrea, M.D., Falcon, W.P. \& Naylor, R.L. (2008) Prioritizing climate change adaptation needs for food security in 2030. Science, 319, 607-610.

Long, S.P., Ainsworth, E.A., Leakey, A.D.B., Nosberger, J. \& Ort, D.R. (2006) Food for thought: lower-than-expected crop yield stimulation with rising $\mathrm{CO} 2$ concentrations. Science, 312, 1918-1921.

Midgley, G.F., Hannah, L., Millar, D., Rutherford, M.C. \& Powrie, L.W. (2002) Assessing the vulnerability of species richness to anthropogenic climate change in a biodiversity hotspot. Global Ecology and Biogeography, 11, 445-451.

Muller, M., Schreiner, B., Smith, L., van Koppen, B., Sally, H., Aliber, M., Cousins, B., Tapela, B., van der Merwe-Botha,
M., Karar, E. \& Pietersen, K. (2009) Water security in South Africa. In: Working paper series No.12. Development planning division, DBSA, Midrand.

Nakicenovic, N. \& Swart, R. (2000) Special report on emissions scenarios. Cambridge University Press, Cambridge.

Neke, K.S. \& Du Plessis, M.A. (2004) The threat of transformation: quantifying the vulnerability of grasslands in South Africa. Conservation Biology, 18, 466-477.

Olmstead, A.L. \& Rhode, P.W. (2011) Adapting North American wheat production to climatic challenges, 18392009. Proceedings of the National Academy of Sciences United States of America, 108, 480-485.

Parmesan, C. \& Yohe, G. (2003) A globally coherent fingerprint of climate change impacts across natural systems. Nature, 421, 37-42.

Paterson, J.S., Araujo, M.B., Berry, P.M., Piper, J.M. \& Rounsevell, M.D.A. (2008) Mitigation, Adaptation, and the Threat to Biodiversity. Conservation Biology, 22, 1352-1355.

Pearson, R.G. \& Dawson, T.P. (2003) Predicting the impacts of climate change on the distribution of species: are bioclimate envelope models useful? Global Ecology and Biogeography, 12, 361-371.

Pence, G.Q.K., Botha, M.A. \& Turpie, J.K. (2003) Evaluating combinations of on-and off-reserve conservation strategies for the Agulhas Plain, South Africa: a financial perspective. Biological Conservation, 112, 253-273.

Phillips, S.J., Anderson, R.P. \& Schapire, R.E. (2006) Maximum entropy modeling of species geographic distributions. Ecological Modelling, 190, 231-259.

Phillips, S.J., Williams, P., Midgley, G. \& Archer, A. (2008) Optimizing dispersal corridors for the cape proteaceae using network flow. Ecological Applications, 18, 1200-1211.

Ramankutty, N., Foley, J.A. \& Olejniczak, N.J. (2002) People on the land: changes in global population and croplands during the 20(th) century. Ambio, 31, 251-257.

Rose, D. \& Charlton, K.E. (2002) Prevalence of household food poverty in South Africa: results from a large, nationally representative survey. Public Health Nutrition, 5, 383-389.

Schulze, R.E. \& Horan, M.J.C. (2010) Methods I: delineation of South Africa, Lesotho and Swaziland into Quinary Carchments. Methodological approaches to assessing eco-hydrological responses to climate change in South Africa. WRC Report 1562/1/10 (ed. by R.E. Schulze, B.S. Hewitson, K.R. Barichievy, M.A. Tadross, R.P. Kunz, M.J.C. Horan and T.G. Lumsden). Water Resources Commission, Pretoria, South Africa.

SIQ. (2007) Point frame sampling: producer independent crop estimate system (PICES). Available at: http://www.SIQ.co.za (accessed 1 September 2009).

SIRI. (1987) Land type series. Memoirs on the Agricultural Natural Resources of South Africa. In. Soil and Irrigation Research Institute, Department of Agriculture and Water Supply, Pretoria, South Africa.

Thomas, C.D., Cameron, A., Green, R.E., Bakkenes, M., Beaumont, L.J., Collingham, Y.C., Erasmus, B.F.N., De SIQueira, M.F., Grainger, A., Hannah, L., Hughes, L., 
Huntley, B., Van Jaarsveld, A.S., Midgley, G.F., Miles, L., Ortega-Huerta, M.A., Peterson, A.T., Phillips, O.L. \& Williams, S.E. (2004) Extinction risk from climate change. Nature, 427, 145-148.

Thuiller, W., Brotons, L., Araujo, M.B. \& Lavorel, S. (2004) Effects of restricting environmental range of data to project current and future species distributions. Ecography, 27, 165-172.

Turner, W.R., Bradley, B.A., Estes, L.D., Hole, D.G., Oppenheimer, M. \& Wilcove, D.S. (2010) Climate change: helping nature survive the human response. Conservation Letters, 3 , 304-312.

Warren, D.L. \& Seifert, S.N. (2011) Ecological niche modeling in Maxent: the importance of model complexity and the performance of model selection criteria. Ecological Applications, 21, 335-342.

Wilson, W.W., Koo, W., Dahl, B. \& Taylor, R. (2008) Impacts of ethanol expansion on cropping patterns and grain flows. Review of Agricultural Economics, 30, 642-663.

Ziska, L.H. (in press) Climate change, carbon dioxide and global crop production: food security and uncertainty. Handbook on climate change and agriculture (ed. by A. Dinar and R. Mendelson). Edward Elgar, Cheltenham, UK.

\section{SUPPORTING INFORMATION}

Additional Supporting Information may be found in the online version of this article:

Appendix S1 Sensitivity to ensemble model threshold.

Appendix S2 A2 Emission Scenario Results.

Figure S1 The effect on changing the ensemble model suitability threshold on estimated land area.
Figure S2 Changes in climatic suitability for non-irrigated maize in South Africa based on the A2 emissions scenario.

Figure S3 Changes in climatic suitability for non-irrigated wheat in South Africa based on the A2 emissions scenario.

Figure S4 Changes in climatic suitability for non-irrigated, high-productivity wheat based on the A2 emissions scenario.

As a service to our authors and readers, this journal provides supporting information supplied by the authors. Such materials are peer-reviewed and may be re-organized for online delivery, but are not copy-edited or typeset. Technical support issues arising from supporting information (other than missing files) should be addressed to the authors.

\section{BIOSKETCH}

Bethany Bradley is an assistant professor of Environmental Conservation at the University of Massachusetts, Amherst. She is interested in how global change affects species distribution, and the implications for biological conservation.

Author contributions: B.A.B., M.O., W.R.T. and D.S.W. conceived of the study. L.D.E., D.G.H., S.H., R.E.S. and M.A.T. collected, compiled or contributed data. B.A.B. conducted the analyses with help from L.D.E. B.A.B. wrote the manuscript with help from L.D.E., D.G.H., S.H., M.O., W.R.T. and D.S.W.

Editor: Graeme Cumming 